\title{
INFLUENCE OF THE CURING METHOD ON THE POST- POLYMERIZATION SHRINKAGE STRESS OF A COMPOSITE RESIN
}

Leonardo Gonçalves CUNHA ${ }^{1}$, Roberta Caroline Bruschi ALONSO ${ }^{2}$, Eduardo José Carvalho de SOUZA-JUNIOR ${ }^{3}$, Ana Christina Elias Claro NEVES ${ }^{1}$, Lourenço CORRER-SOBRINHO ${ }^{4}$, Mário Alexandre Coelho SINHORETI ${ }^{5}$

1- DDS, MSc, PhD, Department of Prosthodontics, University of Taubaté, Taubaté, SP, Brazil.

2- DDS, MSc, PhD, Department of Restorative Dentistry, Dental Materials Division, Piracicaba Dental School, State University of Campinas -UNICAMP, Piracicaba, SP, Brazil.

3- Graduate Student, Federal University of Bahia, Dental School, Salvador, BA, Brazil.

4- DDS, MSc, PhD, Full Professor, Department of Restorative Dentistry, Dental Materials Division, Piracicaba Dental School, State University of Campinas -UNICAMP, Piracicaba, SP, Brazil.

5- DDS, MSc, PhD, Associate Professor, Department of Restorative Dentistry, Dental Materials Division, Piracicaba Dental School, State University of Campinas -UNICAMP, Piracicaba, SP, Brazil.

Corresponding address: Dr. Leonardo Gonçalves Cunha - Rua Expedicionário Ernesto Pereira, 110 - 12020-330, Taubaté, SP, Brasil.

Phone: 55+12-3625-4149 - Fax: 55+12-3632-4968 - e-mail: leonardogcunha@yahoo.com

Received: January 18, 2008 - Modification: March 12, 2008 - Accepted: March 29, 2008

\begin{abstract}
$T_{\text {he }}$

he aim of this study was to evaluate the effect of different curing methods on the stress generated by the polymerization shrinkage of a restorative composite in two moments: immediately after light exposure and after 5 min. Photoactivation was performed using two different light sources: (1) xenon plasma arc (PAC) light $\left(1,500 \mathrm{~mW} / \mathrm{cm}^{2}-3 \mathrm{~s}\right)$ and (2) a quartz-tungstenhalogen $(\mathrm{QTH})$ light with three light-curing regimens: continuous exposure $\left(40 \mathrm{~s}\right.$ at $\left.800 \mathrm{~mW} / \mathrm{cm}^{2}-\mathrm{CL}\right)$; soft-start (10 s at 150 $\mathrm{mW} / \mathrm{cm}^{2}$ and $30 \mathrm{~s}$ at $\left.800 \mathrm{~mW} / \mathrm{cm}^{2}-\mathrm{SS}\right)$ and intermittent light [cycles of $4 \mathrm{~s}\left(2 \mathrm{~s}\right.$ with light on at $600 \mathrm{~mW} / \mathrm{cm}^{2}$ and $2 \mathrm{~s} \mathrm{of} \mathrm{light} \mathrm{off),}$ for $80 \mathrm{~s}-\mathrm{IL}]$. The composite resin was applied between two 5-mm diameter metallic rods, mounted in a servohydraulic machine. The maximum stress was recorded immediately after light exposure (FF) and after 5 min (5F). The results were submitted to ANOVA and Tukey's test (5\%). For each method, the results obtained in FF and 5F were, respectively: CL (3.58 and $4.46 \mathrm{MPa}$ ); SS (2.99 and 4.36 MPa); IL (3.11 and 4.32 MPa) and PAC (0.72 and 3.27 MPa). The stress generated by the polymerization shrinkage during light exposure can be associated with the photoactivation method used. A significant increase in the stress level was observed during the post-curing period up to $5 \mathrm{~min}$, for all evaluated methods.
\end{abstract}

Key words: Composite resins. Stress. Post-curing.

\section{INTRODUCTION}

While composite restorations have become popular because of their esthetic appeal, some drawbacks inherent to the polymerization reaction still need to be overcome. As the material cures, an increase in stiffness accompanying volumetric changes that are confined by the cavity walls results in stresses that challenge the integrity of the bond between the composite restoration and the tooth ${ }^{1}$. Even in cases where bonding integrity is maintained, contraction stress is a potential source for problems, such as cuspal deflection ${ }^{12}$.

The magnitude of such stress is dependent upon several factors related to cavity geometry $(\mathrm{C} \text {-factor })^{6}$, material characteristics, such as monomer composition, catalyst concentration and filler type and content, and restorative technique (placement technique and light curing method, for the photoactivated systems) $)^{2}$. The clinician only has control over some of these factors, such as the irradiance and exposure time ${ }^{24}$.

In an attempt to reduce polymerization shrinkage stress, different curing methods have been suggested. Traditionally, quartz-tungsten-halogen (QTH) lights have been used in a continuous output mode while emitting a fairly high irradiance ${ }^{6,7}$. However, radiation from this type of source can also be applied in different manners. The "softstart" method employs an initial low irradiance for a specific duration followed by a high one equivalent in value to that of the continuous phase ${ }^{9}$. Previous studies have associated this method with better marginal integrity of composite restoratives ${ }^{13,15}$. Intermittent light method alternates periods of light on and light off. The light-off periods promote a 
reduction of the polymerization rate, which can be responsible for slower stress formation and higher probability of bonding preservation ${ }^{16}$.

In addition to the QTH light, xenon plasma arc (PAC) is claimed as an alternative light source, associated with high irradiance (up to $\left.1,300 \mathrm{~mW} / \mathrm{cm}^{2}\right)^{21}$ levels during a short exposure, from 3 to $9 \mathrm{~s}^{14,20}$. According to the manufacturers, 3 s using PAC light source is equivalent to $30-45 \mathrm{~s}$ of irradiation using a conventional QTH source with irradiance level $=500 \mathrm{~mW} / \mathrm{cm}^{2,10}$. Short curing times with high irradiance in composite resin are desirable by many dentists, however, it can produce inadequate polymerization and worse marginal adaptation, increasing the microleakage along the dentin margins ${ }^{18,20}$.

In addition, the stress generated from the polymerization shrinkage of restorative composites is not limited to the period of light exposure. Previous studies have shown a continuous increase of stress for different periods of time after the end of photoactivation ${ }^{13,26-27}$. The increase of the stress level after the end of light exposure is associated with an additional polymerization and with the occurrence

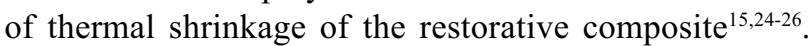
Therefore, the aim of this study was to evaluate the effect of different curing methods on the stress generated by the polymerization shrinkage of a composite resin immediately after light exposure period and 5 min after the end the photoactivation. All curing methods were hypothesized to promote a significant increase of the stress after the end of light exposure, but showing different patterns and levels of stress generation.

\section{MATERIALAND METHODS}

Filtek Z250 composite resin (3M/ESPE, St. Paul, MN, USA) was used for fabrication of the specimens submitted to the different curing methods.

A cylindrical metallic device (Figure 1B), connected to the actuator, was attached to the upper portion of a universal testing machine (Instron, model 4411, Canton, MA, USA). One of the ends of the metallic device had a flat and plane circular area. Before the test, the flat area of each metallic device was polished with 600 -grit aluminum oxide sandpapers and pressure blowing with a $50-\mu \mathrm{m}$ aluminum oxide particle stream.

After these two steps, one coat of Scothbond MultiPurpose adhesive system (3M/ESPE) was applied in each circular area of the metallic device. The adhesive layer was cured prior to the test for $10 \mathrm{~s}$. In the inferior area of the testing machine (Figure 1F), a metallic mould with a coneshaped 8-mm-diameter central hole was fixed (Figure 1D). This region was filled completely with the same composite and a $1 \mathrm{~kg}$ load was applied to obtain a standardized surface and remove composite excesses. This increment of composite was cured prior to the accomplishment of the test. It represented the bond region of the composite specimen to the inferior area of the testing machine. The composite specimens were prepared in transparent plastic conduits ( $5 \mathrm{~mm}$ in diameter and $5 \mathrm{~mm}$ height), which were filled with the material until its complete filling. Standardization of the composite volume used in the different specimens was performed in the universal testing machine, prior to testing, by controlling specimen size.

Thereafter, the conduit filled with the uncured composite was placed between the two extremities of the machine, maintaining a distance of $5 \mathrm{~mm}$ (Figure 1E). Two units were simultaneously used for curing in opposed sides of the specimen (Figure 1C). The evaluated curing methods are described in Table 1. The stress value showed in the test system was recorded immediately after photoactivation. An additional time of $5 \mathrm{~min}$ was waited for each specimen, and the stress value generated after this period was recorded again. The stress values recorded in kgf were converted to MPa with the equation: stress value $(\mathrm{kgf}) / \mathrm{area}$ of the specimen $\left(\mathrm{cm}^{2}\right) \times 0.098$.

For every new specimen, a new cylindrical metallic device was used in the superior area and a new composite layer was prepared in the inferior area. Ten specimens were prepared per group.

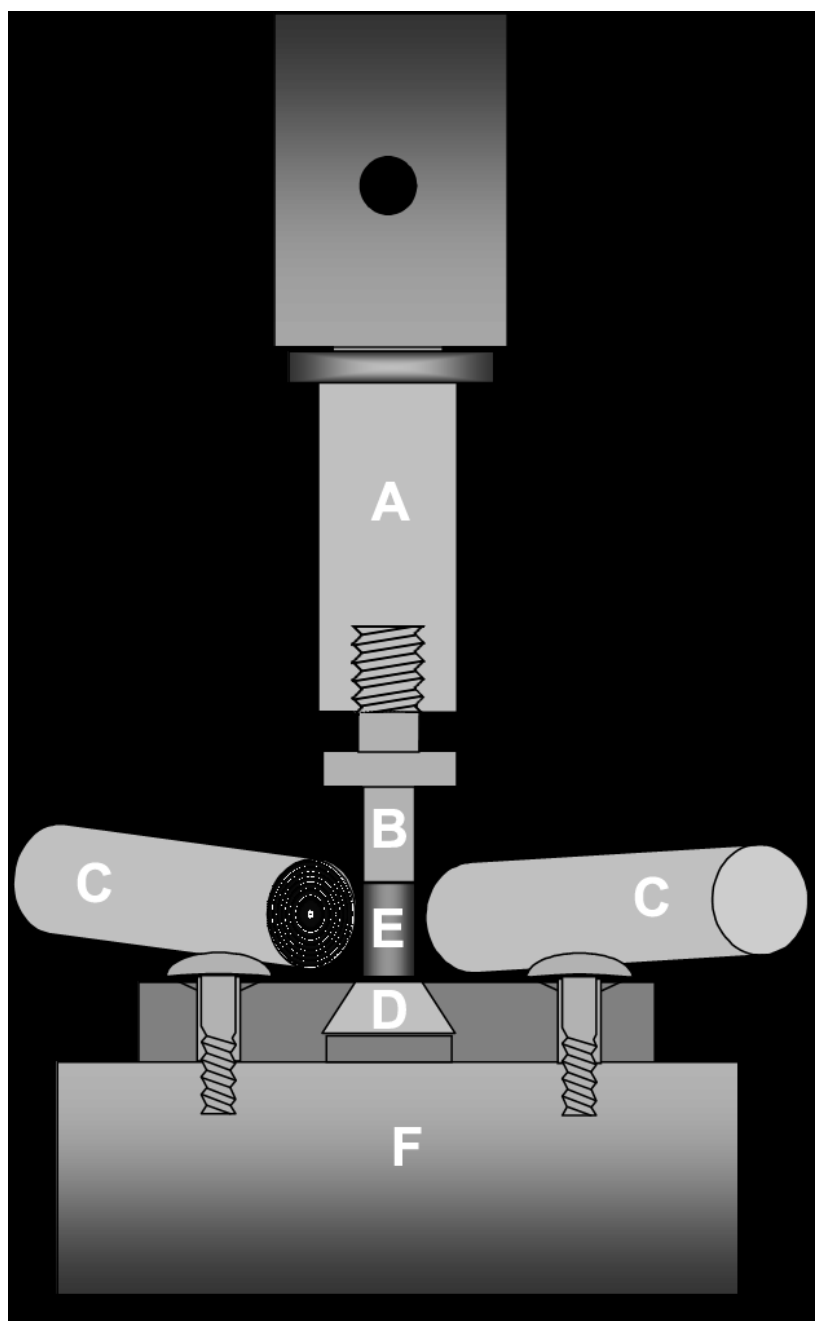

FIGURE 1- Polymerization stress testing configuration. (A) upper portion of the system, connected to the load cell; (B) cylindrical metallic device; (C) photoactivation units in position; (D) lower metallic mould with central hole; (E) composite specimen; $(F)$ lower portion of the system 
TABLE 1- Light-curing methods with their outputs and respective manufacturers

\begin{tabular}{llll}
\hline Curing Method & Curing Protocol & Equipment & Manufacturer \\
\hline $\begin{array}{lll}\text { Continuous QTH light } \\
\text { Stepped QTH light }\end{array}$ & $800 \mathrm{~mW} / \mathrm{cm}^{2}$ for $40 \mathrm{~s}$ & XL 2500 & 3M, St. Paul, USA \\
& $10 \mathrm{~s}-150 \mathrm{~mW} / \mathrm{cm}^{2}$ & XL 2500 & $3 \mathrm{M}$, St. Paul, USA \\
Intermittent QTH light & $30 \mathrm{~s}-800 \mathrm{~mW} / \mathrm{cm}^{2}$ & & Demetron Res Corp, \\
Xenon plasma arc (PAC) & $600 \mathrm{~mW} / \mathrm{cm}^{2}$ in cycles of 4s, & Optilux 150 & Danbury, USA \\
\hline
\end{tabular}

TABLE 2- Stress means in MPa (SD) generated by the photoactivation methods in the both time points

$\begin{array}{ll}\text { Curing Method Period } & \text { Ped }\end{array}$

Immediately after light exposure

5 min after light exposure

$\begin{array}{lll}\text { Continuous QTH light } & 3.58 \mathrm{a}, \mathrm{A}(0.54) & 4.46 \mathrm{a}, \mathrm{B}(1.09) \\ \text { Stepped QTH light } & 2.99 \mathrm{a}, \mathrm{A}(0.30) & 4.36 \mathrm{a}, \mathrm{B}(0.40) \\ \text { Intermittent QTH light } & 3.11 \mathrm{a}, \mathrm{A}(0.31) & 4.32 \mathrm{a}, \mathrm{B}(0.49) \\ \text { Xenon plasma arc } & 0.72 \mathrm{~b}, \mathrm{~A}(0.14) & 3.27 \mathrm{~b}, \mathrm{~B}(0.58)\end{array}$

Different lowercase letters in columns and uppercase letters in rows indicate statistically significant difference (Tukey's test; $p<0.05)$.

The stress data obtained for the different curing methods were submitted to one-way ANOVA and Tukey's test. Significance level was set at $5 \%$.

\section{RESULTS}

The mean stress values generated by composite shrinkage after the end of the curing period and after the additional time of 5 min are presented on Table 2.

All curing methods presented significantly higher mean stress values $(\mathrm{p}<0.05)$ after the additional time of $5 \mathrm{~min}$, in comparison to the results obtained immediately after the end of light exposure.

PAC curing method presented the highest stress increase - from $0.72 \mathrm{MPa}$ (end of light exposure) to 3.27 MPa (after 5 min) -, corresponding to an increase of $78 \%$. Continuous QTH curing method presented the least stress increase - from 3.58 $\mathrm{MPa}$ (end of light exposure) to $4.46 \mathrm{MPa}$ (after $5 \mathrm{~min}$ ), corresponding to a percent increase of $19.7 \%$. Intermittent QTH curing method showed a stress increase from $3.11 \mathrm{MPa}$ (end of light exposure) to $4.32 \mathrm{MPa}$ (after $5 \mathrm{~min}$ ), corresponding to an increase of $25.7 \%$. For soft-start QTH curing method, the stress values ranged from $2.99 \mathrm{MPa}$ (end of light exposure) to $4.36 \mathrm{MPa}$ (after $5 \mathrm{~min}$ ), a percentage increase of $31 \%$.

At the end of the light exposure and after the 5-minute period, no statistically significant differences were observed ( $p>0.05$ ) among the curing methods regarding the generated stress values, except for PAC, which produced significantly lower values $(\mathrm{p}<0.05)$ than the other methods.

\section{DISCUSSION}

Polymerization shrinkage still represents the main disadvantage of composite resins. Shrinkage is associated with the decrease of the spaces among the monomers during the formation of the polymeric chains of the organic matrix ${ }^{19}$. When shrinkage takes place under conditions of confinement, stresses are generated, produced by bonding to cavity walls ${ }^{3}$.

Sakaguchi and Ferracane ${ }^{23}$ (1998) observed a high correlation between shrinkage stress and radiant exposure $\left(r^{2}=0.97\right)$. However, based on the results of the present study, stress formation is not limited to the light-exposure time because a significant increase in stress was observed after the end of the photoactivation. The 5-minute post-light exposure period was responsible for a mean additional stress formation from 19.7 to $78 \%$. Stress generated after the end of the light exposure is associated with a continuity of the polymerization reaction in the absence of light (additional polymerization) and with the occurrence of a temperature decrease in the composite mass (thermal shrinkage) ${ }^{23,26}$.

According to Halvorson ${ }^{13}$ (2002), the additional polymerization from $5 \mathrm{~min}$ to $24 \mathrm{~h}$ represents, depending on the material, as much as $19-26 \%$ of the final conversion. Approximately 37 and $62 \%$ of this process occurs within the first 5 and $60 \mathrm{~min}$, respectively. During light exposure, the rate of free radicals from acrylates and metacrylates follows a 
characteristic pattern throughout the course of the reaction due to diffusion limitations on the reacting species. This pattern is manifested early in the reaction by an increase in the radical concentration. As a consequence, the rate of polymerization accelerates (autoacceleration) to a maximum in spite of the decrease in monomer concentration. After light emission, the dimethacrylate molecules are probably able to diffuse and react with reactive ends even after their viscosity has increased ${ }^{13}$. After having passed through this maximum, the rate of radical propagation becomes diffusion limited and the polymerization rate decelerates, often towards a limited conversion in the presence of unreacted monomer and significant population of radicals ${ }^{13}$.

Curing methods associated with longer light-exposure times were related to a reduced post-polymerization shrinkage stress. To such methods, a higher development of the degree of conversion, and, consequently, of stresses occurred during photoactivation. Therefore, a less amount of conversion and stresses were observed after the end of the light exposure, considering the high correlation between conversion and stress $^{25}$. In addition, such situation could be related to the mobility of reactive molecules in the polymer network. During polymerization, free radicals located at functional groups of unreacted molecules are trapped within the polymer network due to the rapid increase in viscosity ${ }^{17,26}$. For postpolymerization, unreacted molecules with free radicals need to be sufficiently mobile in order to make contact with other reactive molecules in the polymer network. The composites with higher degree of conversion are considered to form a more rigid network than specimens with lower conversion. Therefore, in the initially highly polymerized composites the chance for the residual unpolymerized monomers to be involved in further reaction is lower. Consequently, the inverse is also true, with a higher amount of post-polymerization when the reaction is advancing slowly ${ }^{26}$.

The findings of the present study confirmed these considerations. From the results of a previous study ${ }^{8}$, testing the same curing methods, continuous QTH light curing method was associated with the highest degree of conversion. In the present study, this curing method was related to the smallest percentage of post-polymerization stress, with an increase of $19.7 \%$. On the other hand, PAC, associated with a low degree of conversion during the light exposure in the previous study ${ }^{8}$, was related to the highest level of postpolymerization stress, showing an increase of $78 \%$ in our experiment. In addition, comparing both curing methods, a previous study observed a lower mean hardness value associated with PAC when compared to continuous QTH light curing ${ }^{28}$. The hardness measurement can be used to test, indirectly, the degree of conversion of a composite. Therefore, the significantly lower maximum stress generated by PAC after $5 \mathrm{~min}(3.27 \mathrm{MPa})$, when compared to continuous QTH light (4.46 MPa), may be related to a lower degree of conversion associated with the PAC method.

For the modulated curing methods, soft-start and intermittent QTH light, a delay of the reaction contributed to slow down the development of shrinkage stress to its ultimate value. In addition, the time period for viscous flow was extended $^{11}$. Soft-start curing method is an example of this situation. The period of initial cure in reduced irradiance ( 150 $\mathrm{mW} / \mathrm{cm}^{2}$ ) was responsible for a slower stress generation, associating this method with the second smallest mean of stress generated during the light exposure period (2.99 MPa). However, after $5 \mathrm{~min}$, the stress value (4.36 MPa) was similar to that of continuous QTH light method. The percent increase in the post-polymerization for soft-start QTH light method was $31.5 \%$. Cunha, et al. ${ }^{8}$ (2003) observed no statistically significant difference in the hardness values between continuous and soft-start QTH light-curing methods. The hardness test can be used to assess, indirectly, the degree of conversion of a composite. Therefore, the equivalent values of stress generated after 5 min with these two methods are associated with a high correlation $\left(r^{2}>0.99\right)$ between the degree of conversion and generated stress, as concluded by Silikas, et al. ${ }^{25}(2000)$.

The same situation can be observed with intermittent QTH light method. Light exposure in cycles was responsible for a slower polymerization, with low polymerization rate. Therefore, at the end of light exposure, the stress value $(3.11 \mathrm{MPa})$ was lower to that observed for continuous QTH light method. This situation is caused by a delay of the polymerization reaction, which will contribute to slow down the development of shrinkage stress to its ultimate value. The percent increase in the post-polymerization period for intermittent QTH light method was $25.7 \%$.

An interesting finding of this study was that modulated curing methods tend to have lower stress generation during light exposure. Immediately after the end of light emission, a reduction of $17 \%$ and $13 \%$ in the total stress generated, for Stepped QTH light and Intermittent QTH light, respectively, was observed, both compared to continuous QTH light. For the latter, the reaction might have evolved too fast, virtually eliminating the opportunity for viscous flow, leading to a dramatic increase in stiffness after a relatively low degree of conversion $^{3}$. As a result, stress develops almost immediately after polymerization is triggered; so, most part of the monomerto-polymer conversion and hence the stress, occurs after the polymer matrix has reached a significant level of rigidity ${ }^{3}$. However, for the modulated methods, the initial low irradiance or light exposure in cycles led to a decrease in the initial polymerization, reflected as a reduction in the stress rate, thereby modifying the generation and distribution of stresses, as reported elsewhere ${ }^{6}$. In addition, the reduction in the stress rate has been associated with higher bond strength of composite restorative materials ${ }^{7}$.

Stress generation after the end of the light exposure period may also be dependent on thermal shrinkage due to heat $\operatorname{loss}^{4}$. The heat supplied during the light exposure period promotes the expansion of the composite mass due to the increase of its internal temperature. At the end of this period, the loss of internal heat causes volumetric contraction, with consequent stress generation ${ }^{4,5,23}$, as observed in this study. Therefore, curing methods associated with high light-curing temperatures, such as continuous QTH light, were related to a more significant occurrence of thermal shrinkage due to a higher supply of heat during the light exposure, with 
consequent higher shrinkage of the composite mass at the end of this period.

\section{CONCLUSION}

The first hypothesis tested in this study, referring to the existence of a significant increase in the stress generated after the end of light exposure was validated by the results. The percent increase in the shrinkage stress ranged from 19.7 to $78 \%$. The second hypothesis tested in this study was also validated, because each method was related to a different pattern of stress generation. In both periods, during light exposure and after light exposure, these patterns were related to the degree of conversion and to the thermal shrinkage level promoted by each method.

\section{REFERENCES}

1- Alonso RC, Cunha LG, Correr GM, Goes MF, Correr-Sobrinho L, Puppin-Rontani RM, et al. Association of photoactivation methods and low modulus resin liners on marginal adaptation of composite restorations. Acta Odontol Scand. 2004;62:298-304.

2- Alonso RC, Correr GM, Cunha LG, Moraes Souto Pantoja CA, Puppin-Rontani RM, Sinhoreti MA. Modulated photoactivation methods: effect on marginal and internal gap formation of restorations using different restorative composites. J Biomed Mater Res B Appl Biomater. 2007;82:346-51.

3- Braga RR, Ballester RY, Ferracane JL. Factors involved in the development of polymerization contraction stress in resin-composites: a systematic review. Dent Mater. 2005;21:962-70.

4- Cehreli MC, Canay S. Comparison of post-gel shrinkage strains in light-polymerized composite resins. J Prosthet Dent. 2002;88:461-6.

5- Chen HY, Manhart J, Hickel R, Kunzelmann KH. Polymerization contraction stress in light-cured packable composite resins. Dent Mater. 2001;17:253-9.

6- Cunha LG, Alonso RC, Pfeifer CS, Correr-Sobrinho L, Ferracane JL Sinhoreti MA. Contraction stress and physical properties development of a resin-based composite irradiated using modulated curing methods at two C-factor levels. Dent Mater. 2008;24:392-8.

7- Cunha LG, Alonso RC, Pfeifer CS, Correr-Sobrinho L, Ferracane JL Sinhoreti MA. Modulated photoactivation methods: Influence on contraction stress, degree of conversion and push-out bond strength of composite restoratives. J Dent. 2007;35:318-24.

8- Cunha LG, Sinhoreti MAC, Consani S, Sobrinho LC. Effect of different photoactivation methods on the polymerization depth of a light-activated composite Oper Dent. 2003;28:155-9.

9- Dall'magro E, Sinhoreti MA, Correr AB, Correr-Sobrinho L, Consani S, Puppin-Rontani RM. Effect of different initial light intensity by the soft-start photoactivation on the bond strength and Knoop hardness of a dental composite. Braz Dent J. 2007;18:107-12.

10 - Den-Mat. Rembrandt Sapphire Curing Light Unit: Operator's Manual. Den-Mat Corporation, Santa Maria, CA; 2001 p. 1-15.

11 - Feilzer AJ, Dooren LH, de Gee AJ, Davidson CL. Influence of light intensity on polymerization shrinkage and integrity of restorationcavity interface. Eur J Oral Sci. 1995;103:322-6.
12- Gonzales-Lopez S, Lucena-Martin C, de Haro-Gasquet F, VilchezDiaz MA, de Haro-Munoz C. Influence of different composite restoration techniques on cuspal deflection: an in vitro study. Oper Dent. 2004;29:656-60.

13 - Halvorson RH, Erickson RL, Davidson CL. Energy dependent polymerization of resin-based composite. Dent Mater. 2002;18:4639

14- Hofmann N, Hugo B, Schubert K, Klaiber B. Comparison between a plasma arc light source and conventional halogen curing units regarding flexural strength, modulus, and hardness of photoactivated resin composites. Clin Oral Investig. 2000;4:140-7.

15- Nalçaci A, Salbas M, Ulusoy N. The effects of soft-start vs continuous-light polymerization on microleakage in Class II resin composite restorations. J Adhes Dent. 2005;7:309-14.

16- Obici AC, Sinhoreti MAC, Goes MF, Consani S, Sobrinho LC. Effect of the photo-activation method on polymerization shrinkage of restorative composites. Oper Dent. 2002;27:192-8.

17- Ottaviani MF, Fiorini A, Mason PN, Corvaja C. Electron spin resonance studies of dental composites: effects of irradiation time, decay over time, pulverization, and temperature variations. Dent Mater. 1992;8:118-24.

18- Park SH, Krejci I, Lutz F. Microhardness of resin composites polymerized by plasma arc or conventional visible light curing. Oper Dent. 2002;27:30-7.

19- Peutzfeldt A. Resin composites in dentistry: the monomer system. Eur J Oral Sci. 1997;105:97-116.

20- Peutzfeldt A, Sahafi A, Asmussen E. Characterization of resin composites polymerized with plasma arc curing units. Dent Mater. 2000; $16: 330-6$.

21 - Price RB, Ehrnford L, Andreou P, Felix CA. Comparison of quartz tungsten-halogen, light emitting diode, and plasma arch curing lights. J Adhes Dent. 2003;5:193-207.

22 - Rueggeberg FA, Caughman WF, Curtis JW Jr. Effect of light intensity and exposure duration on cure of resin composite. Oper Dent. 1994;19:26-32.

23 - Sakaguchi RL, Ferracane JL. Stress transfer from polymerization shrinkage of a chemical-cured composite bonded to a pre-cast composite substrate. Dent Mater. 1998;14:106-11.

24- Sakaguchi RL, Wiltbank BD, Murchison CF. Contraction force rate of polymer composites is linearly correlated with irradiance. Dent Mater. 2004;20:402-7

25- Silikas N, Eliades G, Watts DC. Light intensity effects on resincomposite degree of conversion and shrinkage strain. Dent Mater. 2000;16:292-6.

26- Tarumi H, Imazato S, Ehara A, Kato S, Ebi N, Ebisu S. Postirradiation polymerization of composites containing bis-GMA and TEGDMA. Dent Mater. 1999;15:238-42.

27- Truffier-Boutry D, Demoustier-Champagne S, Devaux J, Biebuyck JJ, Mestdagh M, Larbanois P, et al. A physico-chemical explanation of the post-polymerization shrinkage in dental resins. Dent Mater. 2006;22:405-12

28- Yazici AR, Kugel G, Gul G. The Knoop hardness of a composite resin polymerized with different curing lights and different modes. J Contemp Dent Pract. 2007;8:52-9. 